\title{
Alcohol Use and Co-Use of Other Substances Among Pregnant Females Aged 12-44 Years — United States, 2015-2018
}

Lucinda J. England, $\mathrm{MD}^{1}$; Carolyne Bennett, $\mathrm{MPH}^{1,2}$; Clark H. Denny, $\mathrm{PhD}^{1}$; Margaret A. Honein, $\mathrm{PhD}^{1}$; Suzanne M. Gilboa, PhD ${ }^{1}$; Shin Y. Kim, MPH ${ }^{1}$; Gery P. Guy Jr., PhD ${ }^{3}$; Emmy L. Tran, PharmD ${ }^{1,2}$; Charles E. Rose, PhD ${ }^{4}$; Michele K. Bohm, MPH${ }^{5}$; Coleen A. Boyle, PhD 4

Drinking alcohol during pregnancy can cause fetal alcohol spectrum disorders, including birth defects, behavioral disorders, and impaired cognitive development (1). Little is known about the co-use of other substances by females who drink during pregnancy. CDC used 2015-2018 data from the National Survey on Drug Use and Health (NSDUH) to estimate the overall and trimester-specific prevalence of selfreported drinking in the past 12 months, current drinking, and binge drinking, overall and by trimester, and the co-use of other substances among pregnant females aged $12-44$ years. Past drinking ( 12 months) was reported by $64.7 \%$ of pregnant respondents. Current drinking (at least one drink in the past 30 days) was reported by $19.6 \%$ of respondents who were in their first trimester of pregnancy and $4.7 \%$ of respondents who were in their second or third trimester. Binge drinking (consuming four or more drinks on at least one occasion in the past 30 days) was reported by $10.5 \%$ of first trimester respondents and $1.4 \%$ of second or third trimester respondents. Overall, $38.2 \%$ of pregnant respondents who reported current drinking also reported current use of one or more other substances. The substances used most with alcohol were tobacco and marijuana. Self-reported drinking prevalence was substantially lower among second or third trimester respondents than among first trimester respondents. The American College of Obstetricians and Gynecologists (ACOG) recommends alcohol use and substance use disorders screening for all females seeking obstetric-gynecologic care and counseling patients that there is no known safe level of alcohol use during pregnancy (2).

NSDUH is a nationwide survey that uses multistage and area probability sampling to provide information on tobacco, alcohol, and drug use, and on mental health and other healthrelated issues, among U.S. civilian, noninstitutionalized persons aged $\geq 12$ years. Surveys are conducted in respondents' homes and use computer-assisted interviewing methods. Female respondents report whether they are currently pregnant and the trimester of pregnancy at the time of the interview. Weighted response rates for 2015-2018 ranged from 66.6\% to $69.3 \%$.* $^{*}$

This report focuses on past 12 months drinking, current drinking and binge drinking among pregnant respondents.

\footnotetext{
*https://www.samhsa.gov/data/sites/default/files/NSDUHMethodSummDefsHTML-2015/NSDUH-MethodSummDefsHTML-2015/ NSDUH-MethodSummDefs-2015.htm.
}

\section{INSIDE}

1015 COVID-19 Outbreak Among Employees at a Meat Processing Facility — South Dakota, March-April 2020

1020 Notes from the Field: Characteristics of Meat Processing Facility Workers with Confirmed SARS-CoV-2 Infection — Nebraska, April-May 2020

1023 SARS-CoV-2 Transmission and Infection Among Attendees of an Overnight Camp - Georgia, June 2020

1026 Characteristics and Outcomes of Contacts of COVID-19 Patients Monitored Using an Automated Symptom Monitoring Tool — Maine, May-June 2020

1031 Vital Signs: Clinical Characteristics of Patients with Confirmed Acute Flaccid Myelitis, United States, 2018

1039 Increase in Antiretroviral Therapy Enrollment Among Persons with HIV Infection During the Lusaka HIV Treatment Surge - Lusaka Province, Zambia, January 2018-June 2019

1044 QuickStats

Continuing Education examination available at https://www.cdc.gov/mmwr/mmwr_continuingEducation.html

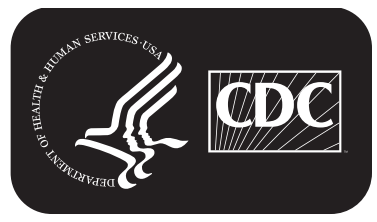

U.S. Department of Health and Human Services Centers for Disease Control and Prevention 
Drinking alcohol during pregnancy and binge drinking in any population are two measures of excessive drinking. ${ }^{\dagger}$ In addition, this report provides estimates of the prevalence of co-use of other substances among respondents who drank alcohol. Respondents who reported ever having an alcoholic beverage were asked how long it had been since they last drank an alcoholic beverage.

This report also examined past 12 months and past 30 days use of other substances, including tobacco (i.e., cigarettes, cigars, smokeless tobacco, and pipes), marijuana, opioids (prescription pain reliever misuse and heroin use), and "other substances," which included cocaine, hallucinogens, inhalants, methamphetamines, and the misuse ${ }^{\S}$ of sedatives, stimulants, and tranquilizers. Other substances were grouped as one category because of the small number of pregnant females who reported using them.

Data were weighted to adjust for nonresponse and to generate nationally representative estimates. Prevalence estimates and 95\% confidence intervals (CIs) for past 12 months drinking, current drinking, and binge drinking were calculated overall and by sociodemographic and pregnancy characteristics

\footnotetext{
$\dagger^{\dagger}$ Excessive drinking by females includes binge drinking (four or more drinks per occasion), heavy drinking (more than one drink per day on average), any drinking by pregnant females, and drinking by females aged <21 years. https:// health.gov/dietaryguidelines/2015/.

${ }^{\S}$ Misuse includes 1) use without a prescription of the respondent's own medication; 2) use in greater amounts, more often, or longer than the respondent was told to take them; or 3) use in any other way a doctor did not direct the respondent to use them.
}

(age, race/ethnicity, income, marital status, education, employment status, insurance status, county urban/rural status, and trimester of pregnancy). Prevalence estimates and 95\% CIs for past 12 months and current drinking alone and with cooccurring substance use among pregnant respondents also were calculated. Analyses were conducted using SAS (version 9.4; SAS Institute) with SUDAAN (version 11.0; RTI International) to account for the complex sampling method used in NSDUH. This activity was reviewed by CDC and conducted consistent with CDC policies and procedures.

Among 99,618 female respondents aged 12-44 years, 3,006 (3\%) reported a current pregnancy. Among pregnant respondents, past 12 months drinking, current drinking, and binge drinking prevalence estimates were $64.7 \%, 9.8 \%$, and $4.5 \%$, respectively (Table 1). Past 12 months drinking was reported by $76.1 \%$ of first trimester respondents and $59.8 \%$ of second or third trimester respondents; current drinking by $19.6 \%$ of first trimester respondents and $4.7 \%$ of second or third trimester respondents; and binge drinking by $10.5 \%$ of first trimester respondents and $1.4 \%$ of second or third trimester respondents ( $\mathrm{p}<0.001$ for all comparisons) (Table 1; Figure).

Among respondents who were pregnant and reported drinking in the past 12 months, $41.7 \%$ also reported using at least one other substance in the past 12 months. The most commonly reported substances were tobacco $(30.3 \%)$, marijuana

\footnotetext{
$\overline{9}$ U.S. Department of Health and Human Services, Title 45 Code of Federal Regulations 46, Protection of Human Subjects.
}

The MMWR series of publications is published by the Center for Surveillance, Epidemiology, and Laboratory Services, Centers for Disease Control and Prevention (CDC), U.S. Department of Health and Human Services, Atlanta, GA 30329-4027.

Suggested citation: [Author names; first three, then et al., if more than six.] [Report title]. MMWR Morb Mortal Wkly Rep 2020;69:[inclusive page numbers]

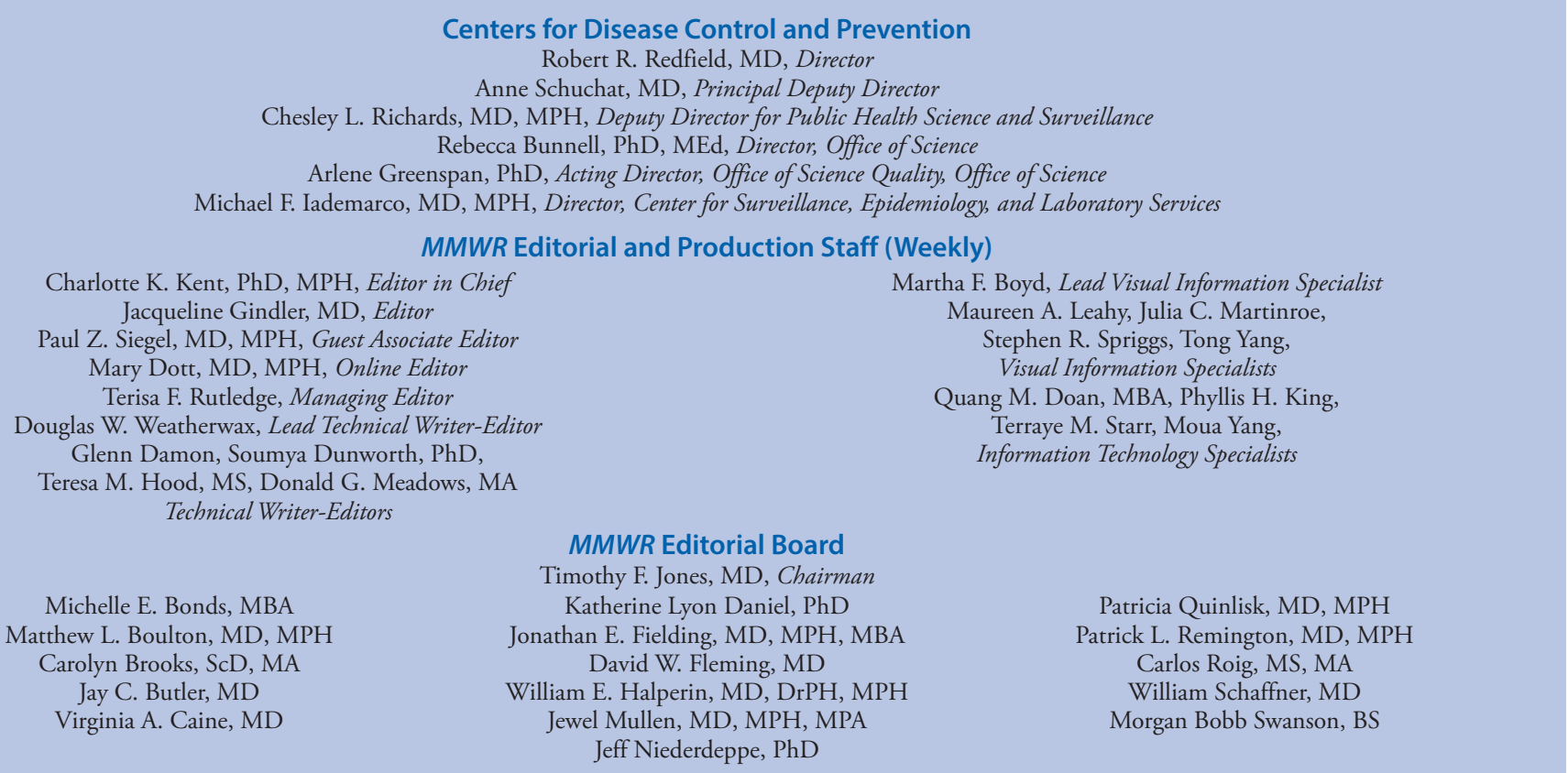


TABLE 1. Weighted prevalence of past 12 months and past 30 days drinking and past 30 days binge drinking in 3,006 pregnant females aged 12-44 years, by selected characteristics — National Survey on Drug Use and Health, United States, 2015-2018

\begin{tabular}{|c|c|c|c|}
\hline \multirow[b]{2}{*}{ Characteristic } & \multicolumn{3}{|c|}{$\%(95 \% \mathrm{Cl})$} \\
\hline & Past 12 months drinking* & Past 30 days drinking* & Past 30 days binge drinking* \\
\hline Overall & $64.7(62.1-67.3)$ & $9.8(8.5-11.1)$ & $4.5(3.7-5.4)$ \\
\hline $\begin{array}{l}\text { Age group (yrs) } \\
<18 \\
18-25 \\
26-34 \\
\geq 35\end{array}$ & $\begin{array}{l}39.0(27.3-52.1) \\
61.2(58.0-64.3) \\
68.2(64.2-72.0) \\
63.1(55.5-70.1)\end{array}$ & $\begin{array}{c}9.9(7.9-12.2) \\
9.4(7.6-11.5) \\
11.1(7.3-16.6)^{\S}\end{array}$ & $\begin{array}{r}6.0(4.5-8.1) \\
3.9(2.9-5.3) \\
{ }^{\dagger}{ }^{\dagger}\end{array}$ \\
\hline $\begin{array}{l}\text { Race/Ethnicity } \\
\text { White, non-Hispanic } \\
\text { Black, non-Hispanic } \\
\text { Hispanic } \\
\text { Other }\end{array}$ & $\begin{array}{l}74.9(71.4-78.0) \\
56.7(51.0-62.3) \\
48.0(42.2-53.7) \\
52.9(44.0-61.7)\end{array}$ & $\begin{array}{c}9.9(8.2-11.8) \\
13.7(9.8-18.9) \\
7.0(4.5-10.7)^{\S} \\
8.4(4.8-14.4)\end{array}$ & $\begin{array}{r}4.0(3.0-5.3) \\
7.0(4.6-10.9)^{\S} \\
\ldots_{+}^{\dagger}\end{array}$ \\
\hline $\begin{array}{l}\text { Income } \$ \\
<\$ 20,000 \\
\$ 20,000-\$ 74,999 \\
\geq \$ 75,000\end{array}$ & $\begin{array}{l}50.5(45.2-55.8) \\
61.6(57.9-65.2) \\
78.3(74.0-82.1)\end{array}$ & $\begin{array}{r}9.7(7.3-12.8) \\
8.7(7.0-10.8) \\
11.4(9.2-14.0)\end{array}$ & $\begin{array}{l}6.3(4.7-8.3) \\
3.9(2.8-5.4) \\
4.3(3.0-6.0)\end{array}$ \\
\hline $\begin{array}{l}\text { Marital status" } \\
\text { Married } \\
\text { Not married }\end{array}$ & $\begin{array}{l}66.2(62.2-70.0) \\
63.6(59.9-67.1)\end{array}$ & $\begin{array}{r}9.0(7.3-11.0) \\
11.0(9.1-13.3)\end{array}$ & $\begin{array}{l}3.1(2.2-4.3) \\
6.5(5.0-8.4)\end{array}$ \\
\hline $\begin{array}{l}\text { Education? } \\
\text { s High school } \\
\text { > High school }\end{array}$ & $\begin{array}{l}49.2(45.3-53.0) \\
73.3(70.0-76.3)\end{array}$ & $\begin{array}{r}8.9(6.9-11.4) \\
10.3(8.8-12.0)\end{array}$ & $\begin{array}{l}5.3(3.8-7.6) \\
4.0(3.1-5.2)\end{array}$ \\
\hline $\begin{array}{l}\text { Employment } \\
\text { Full time } \\
\text { Part time } \\
\text { Unemployed/Other** }\end{array}$ & $\begin{array}{l}76.3(73.1-79.1) \\
62.5(57.2-67.5) \\
53.5(49.3-57.7)\end{array}$ & $\begin{array}{r}11.6(9.7-13.9) \\
8.7(5.8-12.8) \\
8.3(6.4-10.6)\end{array}$ & $\begin{array}{l}4.6(3.4-6.2) \\
3.4(1.9-6.2)^{\S} \\
4.8(3.4-6.6)\end{array}$ \\
\hline $\begin{array}{l}\text { Insurance } \\
\text { Medicaid } \\
\text { Private } \\
\text { Uninsured/Other }{ }^{\dagger \dagger}\end{array}$ & $\begin{array}{l}54.9(51.3-58.5) \\
73.9(70.2-77.3) \\
53.2(46.2-60.1)\end{array}$ & $\begin{array}{r}7.6(6.0-9.5) \\
10.6(8.6-13.0) \\
13.5(9.4-18.9)\end{array}$ & $\begin{array}{c}3.8(2.8-5.0) \\
4.0(3.0-5.5) \\
9.5(5.7-15.4)^{\S}\end{array}$ \\
\hline $\begin{array}{l}\text { Urban/Rural§§ } \\
\text { Metropolitan } \\
\text { Micropolitan } \\
\text { Rural }\end{array}$ & $\begin{array}{l}65.7(61.6-69.5) \\
64.5(60.6-68.2) \\
61.0(55.8-66.0)\end{array}$ & $\begin{array}{r}10.3(8.4-12.7) \\
9.3(7.1-12.0) \\
8.3(5.9-11.7)\end{array}$ & $\begin{array}{l}3.8(2.7-5.4) \\
4.9(3.7-6.6) \\
6.3(3.9-9.8)^{\S}\end{array}$ \\
\hline $\begin{array}{l}\text { Trimester } \\
\text { First } \\
\text { Second or third }\end{array}$ & $\begin{array}{l}76.1(72.7-79.3) \\
59.8(56.5-63.1)\end{array}$ & $\begin{array}{r}19.6(16.8-22.7) \\
4.7(3.5-6.4)\end{array}$ & $\begin{array}{r}10.5(8.5-13.0) \\
1.4(0.9-2.1)\end{array}$ \\
\hline
\end{tabular}

Abbreviation: $\mathrm{Cl}$ = confidence interval.

* Past 12 months use regardless of whether there was also past 30 days use; past 30 days drinking regardless of whether there was also past 30 days binge drinking;

binge drinking $=$ consuming four or more drinks on at least one occasion in the past 30 days.

$\dagger$ Estimates are not presented because the relative standard error was $>30 \%$.

$\S$ Estimate might be unstable because the relative standard error is $20 \%-30 \%$.

I The age group $<18$ years was omitted for income, marital status, education, and employment.

** Other $=$ those not in the labor force.

t+ Other insurance not otherwise specified.

$\S \S$ https://www.ers.usda.gov/data-products/rural-urban-continuum-codes.

१ศ Overall, $1.3 \%$ of females reported an unknown trimester of pregnancy and were not included in the table.

(21.9\%), and opioids (7.0\%) (Table 2). Among respondents who reported current drinking, 38.2\% reported using at least one other substance, most commonly tobacco $(28.1 \%)$ and marijuana (20.6\%) (Table 2).

Overall, $19.6 \%$ of respondents who were pregnant reported past 12 months drinking and tobacco use, $14.2 \%$ reported past 12 months drinking and marijuana use, $4.5 \%$ reported past 12 months drinking and opioid use, $2.7 \%$ reported current drinking and tobacco use, and $2.0 \%$ reported current drinking and marijuana use.

\section{Discussion}

During 2015-2018, approximately half of all pregnant respondents who reported current drinking (drinking in the past 30 days) (9.8\%) also reported binge drinking (4.5\%). Among pregnant females who reported current drinking, $38.2 \%$ also reported current use of one or more other substances, including tobacco, marijuana, opioids, and other substances. The estimates of current drinking and binge drinking among pregnant females are consistent with recent 
FIGURE. Weighted prevalence of past 12 months drinking, past 30 days drinking, and past 30 days binge drinking* among pregnant females ${ }^{\dagger}$ aged $12-44$ years $(N=3,006)$, by trimester - National Survey on Drug Use and Health, United States, 2015-2018

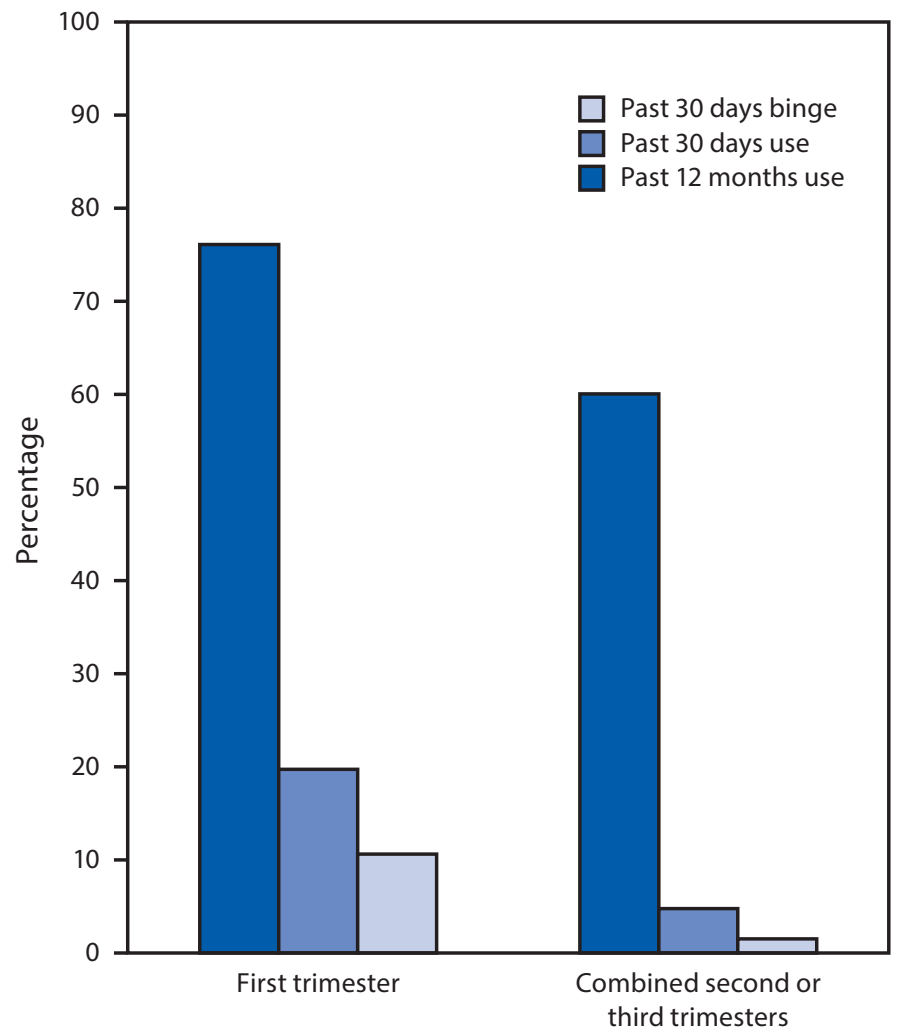

Trimester of pregnancy

\footnotetext{
* For females, binge drinking = four or more drinks per occasion.

† Overall, $1.3 \%$ of pregnant females reported an unknown trimester of pregnancy and were not included in the figure.
}

analyses using data from the 2015-2017 Behavioral Risk Factor Surveillance System, which reported current drinking and binge drinking estimates of $11.5 \%$ and $3.9 \%$, respectively, among pregnant respondents aged 18-44 years (3). The current analysis adds to previous findings by including trimesterspecific estimates showing higher self-reported drinking in first trimester respondents, suggesting that some respondents who drank before pregnancy might have quit by mid-to-late pregnancy, and by providing estimates indicating that co-use of other substances is common.

Few population-based reports consider co-use of other substances among pregnant females who drink alcohol. In this report, current drinking overall and in combination with one or more other substances were substantially lower than past 12 months drinking, suggesting that females decrease their use after they know they are pregnant. Alcohol exposure during pregnancy can adversely affect fetal development, resulting in behavioral disorders, impaired intellectual development, and

\begin{abstract}
Summary
What is already known about this topic?

Drinking alcohol during pregnancy can cause miscarriage, stillbirth, and fetal alcohol spectrum disorders; however, approximately one in nine pregnant females report current drinking. Little is known about the co-use of other substances by females who drink during pregnancy.

What is added by this report?

Pregnant respondents in the first trimester reported higher current alcohol use than did respondents in the second or third trimester. Among first trimester respondents, 19.6\% reported current alcohol use and $10.5 \%$ reported binge drinking; among second or third trimester respondents, current drinking and binge drinking were reported by $4.7 \%$ and $1.4 \%$, respectively. Approximately $40 \%$ of pregnant females reporting current drinking also reported current use of other substances.

What are the implications for public health?

Co-use of other substances is common among females who drink alcohol during pregnancy. Screening and interventions for alcohol and other substances in pregnancy could improve the health of mothers and their children.
\end{abstract}

birth defects (1). It also has been associated with miscarriage and stillbirth (4). Although supporting data are sparse, alcohol exposure combined with exposure to other substances could worsen pregnancy outcomes. Prenatal exposure to substances included in this analysis has been associated with adverse health outcomes, including preterm birth, sudden infant death syndrome, and preterm-related death (exposure to tobacco) (5); low birth weight (tobacco, marijuana) $(5,6)$; and altered fetal brain development (tobacco, marijuana) (5-8). A review of prenatal substance exposure and neuroimaging suggests that in utero exposure to substances other than alcohol, including marijuana, nicotine, cocaine, methamphetamine, opioids, or combinations of substances, is associated with long-term effects on cognition and with altered brain connectivity and white matter deficits (9).

The findings in this report are subject to at least four limitations. First, data are self-reported and therefore subject to social desirability bias; respondents might underreport substance use because of social stigma and legal implications. Second, because NSDUH only ascertains past 12 months and past 30 days substance use in a cross-sectional sample, patterns across individual pregnancies are unknown. Estimates of any substance use during the length of an entire pregnancy would likely be higher than estimates of past 30 days use. Third, limited sample size necessitated the suppression of some prevalence estimates. Finally, some pregnancies might not have been recognized at the time of the interview, resulting in misclassification by pregnancy status. Alcohol use and other substance use presumably 
TABLE 2. Weighted prevalence of substance use patterns (past 12 months and past 30 days) in pregnant females aged $12-44$ years ( $N=3,006 *$ ) who drank alcohol in the past 12 months $\left(n=1,851^{*}\right)$ or the past 30 days $\left(n=282^{*}\right)$ - National Survey on Drug Use and Health, United States, 2015-2018

$\%(95 \% \mathrm{Cl})$

\begin{tabular}{|c|c|c|}
\hline Substance use pattern & Past 12 months drinking ${ }^{\dagger}$ & Past 30 days (current) drinking \\
\hline \multicolumn{3}{|l|}{ All pregnant females $\left(\mathrm{N}=3,006^{*}\right)$} \\
\hline Any alcohol use & $64.7(62.1-67.3)$ & $9.8(8.5-11.1)$ \\
\hline Alcohol use only & $37.7(35.7-39.7)$ & $6.0(5.0-7.2)$ \\
\hline Alcohol and $\geq 1$ additional substance & $27.0(25.1-29.0)$ & $3.7(2.9-4.7)$ \\
\hline \multicolumn{3}{|l|}{ Other substances used $\S$} \\
\hline Tobacco" & $19.6(18.0-21.3)$ & $2.7(2.1-3.6)$ \\
\hline Marijuana & $14.2(12.3-16.3)$ & $2.0(1.4-2.8)$ \\
\hline Opioids** & $4.5(3.5-5.8)$ & —† \\
\hline Other ${ }^{\dagger \dagger}$ & $6.2(5.0-7.7)$ & - \\
\hline \multicolumn{3}{|c|}{ Pregnant females who drank in the past 12 months $\left(n=1,851^{*}\right)$ or in the past 30 days $\left(n=282^{*}\right)$} \\
\hline Alcohol use only & $58.3(56.0-60.6)$ & $61.8(53.9-69.2)$ \\
\hline Alcohol and $\geq 1$ additional substance & $41.7(39.4-44.0)$ & $38.2(30.8-46.1)$ \\
\hline \multicolumn{3}{|l|}{ Other substances used ${ }^{\S}$} \\
\hline Tobacco? & $30.3(28.0-32.8)$ & $28.1(21.7-35.6)$ \\
\hline Marijuana & $21.9(19.0-25.0)$ & $20.6(14.5-28.3)$ \\
\hline Opioids** & $7.0(5.5-8.9)$ & $\mathrm{C}^{\dagger+}$ \\
\hline Other§§ & $9.76(7.8-11.8)$ & —†+ \\
\hline
\end{tabular}

Abbreviation: $\mathrm{Cl}=$ confidence interval.

* Unweighted.

† Past 12 months use, regardless of whether there was also drinking in the past 30 days (current drinking).

$\S$ Not mutually exclusive.

I Includes cigarettes, cigars, or smokeless tobacco.

** Includes prescription pain reliever misuse and heroin use.

${ }^{\dagger \dagger}$ Estimates are not presented because the relative standard error was $>30 \%$.

$\S \S$ Includes use of cocaine, hallucinogens, inhalants, methamphetamines, and the misuse of sedatives, stimulants, and tranquilizers.

are lower in recognized than in unrecognized pregnancies, resulting in underestimation of exposure levels.

The U.S. Preventive Services Task Force recommends alcohol screening and brief behavioral counseling in primary care settings for all adults aged $\geq 18$ years (10). ACOG recommends alcohol use screening for all females seeking obstetric-gynecologic care and counseling patients that there is no known safe level of alcohol use during pregnancy (2). ACOG also recommends routine universal screening for substance use disorders with validated screening tools or through conversations with patients. Although ACOG does not have recommendations specific to polysubstance use, the findings of this report indicate that a substantial percentage of females who use alcohol during early pregnancy also use one or more other substances, especially tobacco or marijuana. Females could benefit from screening and interventions in pregnancy to reduce alcohol and polysubstance use and from referral for those in need of treatment. Successful reduction in substance exposures during pregnancy could improve the health of mothers and their children.

Corresponding author: Lucinda J. England, lbe9@cdc.gov, 770-488-6266.

\footnotetext{
${ }^{1}$ Division of Birth Defects and Infant Disorders, National Center on Birth Defects and Developmental Disabilities, CDC; ${ }^{2}$ Eagle Global Scientific, LLC, San Antonio, Texas; ${ }^{3}$ Division of Overdose Prevention, National Center for Injury Prevention and Control, CDC; ${ }^{4}$ Office of the Director, National Center on Birth Defects and Developmental Disabilities, CDC; ${ }^{5}$ Division of Population Health, National Center for Chronic Disease Prevention and Health Promotion, CDC.
}

All authors have completed and submitted the International Committee of Medical Journal Editors form for disclosure of potential conflicts of interest. No potential conflicts of interest were disclosed.

\section{References}

1. Mattson SN, Bernes GA, Doyle LR. Fetal alcohol spectrum disorders: a review of the neurobehavioral deficits associated with prenatal alcohol exposure. Alcohol Clin Exp Res 2019;43:1046-62. https://doi. org/10.1111/acer. 14040

2. American College of Obstetricians and Gynecologists. ACOG committee opinion no. 633. Alcohol abuse and other substance use disorders: ethical issues in obstetric and gynecological practice. Obstet Gynecol 2015;125:1529-37. https://doi.org/10.1097/01. AOG.0000466371.86393.9b

3. Denny CH, Acero CS, Naimi TS, Kim SY. Consumption of alcohol beverages and binge drinking among pregnant women aged 18-44 years-United States, 2015-2017. MMWR Morb Mortal Wkly Rep 2019;68:365-8. https://doi.org/10.15585/mmwr.mm6816a1

4. Bailey BA, Sokol RJ. Prenatal alcohol exposure and miscarriage, stillbirth, preterm delivery, and sudden infant death syndrome. Alcohol Res Health 2011;34:86-91.

5. US Department of Health and Human Services. The health consequences of smoking - 50 years of progress: a report of the Surgeon General. Atlanta, GA: US Department of Health and Human Services, CDC; 2014. https://www.ncbi.nlm.nih.gov/books/NBK179276/

6. National Academies of Sciences, Engineering, and Medicine. The health effects of cannabinoids: the current state of evidence and recommendations for research. Washington, DC: The National Academies Press; 2017. https://www.nap.edu/catalog/24625/ the-health-effects-of-cannabis-and-cannabinoids-the-current-state 
7. Conner SN, Bedell V, Lipsey K, Macones GA, Cahill AG, Tuuli MG. Maternal marijuana use and adverse neonatal outcomes: a systematic review and meta-analysis. Obstet Gynecol 2016;128:713-23. https:// doi.org/10.1097/AOG.0000000000001649

8. Gunn JK, Rosales CB, Center KE, et al. Prenatal exposure to cannabis and maternal and child health outcomes: a systematic review and meta-analysis. BMJ Open 2016;6:e009986. https://doi.org/10.1136/ bmjopen-2015-009986
9. Morie KP, Crowley MJ, Mayes LC, Potenza MN. Prenatal drug exposure from infancy through emerging adulthood: results from neuroimaging. Drug Alcohol Depend 2019;198:39-53. https://doi.org/10.1016/j. drugalcdep.2019.01.032

10. Curry SJ, Krist AH, Owens DK, et al.; US Preventive Services Task Force. Screening and behavioral counseling interventions to reduce unhealthy alcohol use in adolescents and adults: US Preventive Services Task Force recommendation statement. JAMA 2018;320:1899-909. https://doi. org/10.1001/jama.2018.16789 